\title{
Aural polyps as predictors of underlying cholesteatoma
}

\author{
C M MILROY,* R W T SLACK, $\dagger$ A R MAW, $\dagger$ J W B BRADFIELD* \\ From the *University Department of Pathology and $\dagger$ Department of Otolaryngology, Bristol Royal Infirmary, \\ Bristol
}

SUMMARY In a retrospective study of 96 patients 16 different histological features were examined in 100 aural polyps to see whether some or any could be used to predict the presence or absence of a cholesteatoma underlying the polyp. The patients were divided into those who had cholesteatoma and those who did not, so that discriminatory features were identified. These were combined to make an overall prediction of the probability of a cholesteatoma in the middle ear.

The results showed that any polyp that (i) was composed of raw granulation tissue and (ii) contained keratin as flakes or masses had a $70-80 \%$ probability of being associated with an underlying cholesteatoma. In contrast, when a polyp (i) was composed of a fibrous core, (ii) had a covering epithelium, and (iii) contained glands and lymphoid aggregates, there was a $70-80 \%$ probability of cholesteatoma being absent. This scoring system can be used to help surgeons decide whether surgical exploration of the mastoid should be undertaken.

Cholesteatoma is a serious disorder of the middle ear cleft which comprises a sac filled with keratin and lined by keratinising squamous epithelium. Once the diagnosis is certain the standard treatment is surgery. ${ }^{12}$ The advisability of surgical intervention in these patients, however, can be difficult to assess, especially in children. In some patients the main presenting feature is an aural polyp. A detailed histological examination of aural polyps was therefore made to find out whether the presence or absence of particular features could be used to predict the likelihood of an underlying cholesteatoma.

\section{Material and methods}

One hundred polyps were taken from 96 patients ( 58 men and 38 women) with an age range of 4 to 92 years.

Polyps were removed at diagnostic polypectomy. If the operation was part of a clearance of a known cholesteatoma, rather than polypectomy alone, the material was excluded from study. Material from any patient undergoing a second operation following previous surgery for cholesteatoma was also excluded. Malignant tissue was not included.

Polyps were fixed in formalin, embedded in paraffin wax, and four micron sections were stained with haematoxylin and eosin. Multiple sections were cut where necessary.

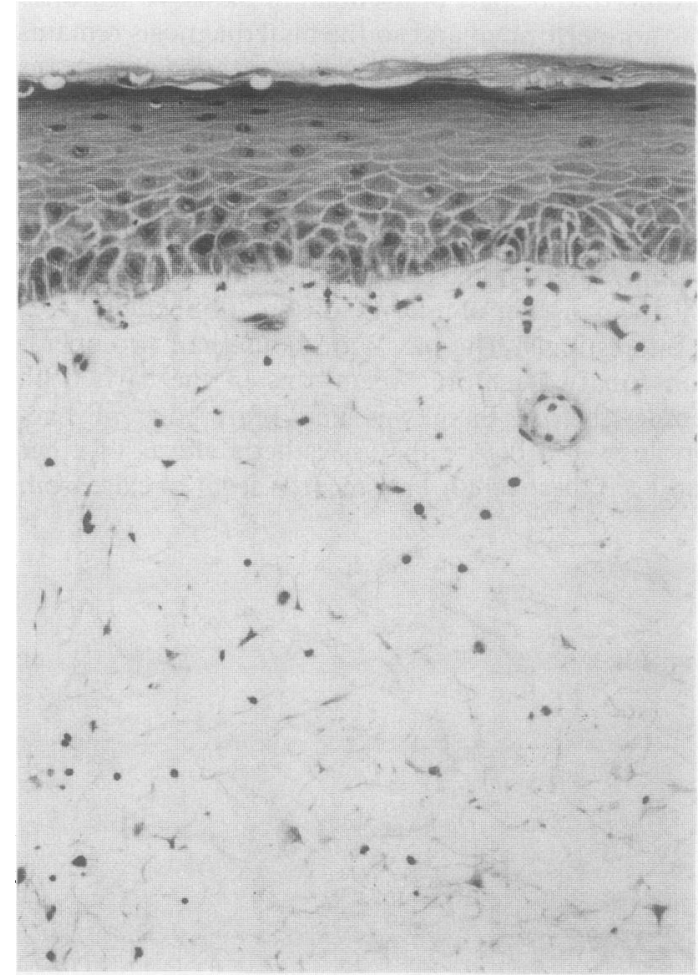

Fig 1 Surface of aural polyp to show surface squamous epithelium and connective tissue core. (Haematoxylin and eosin.) 


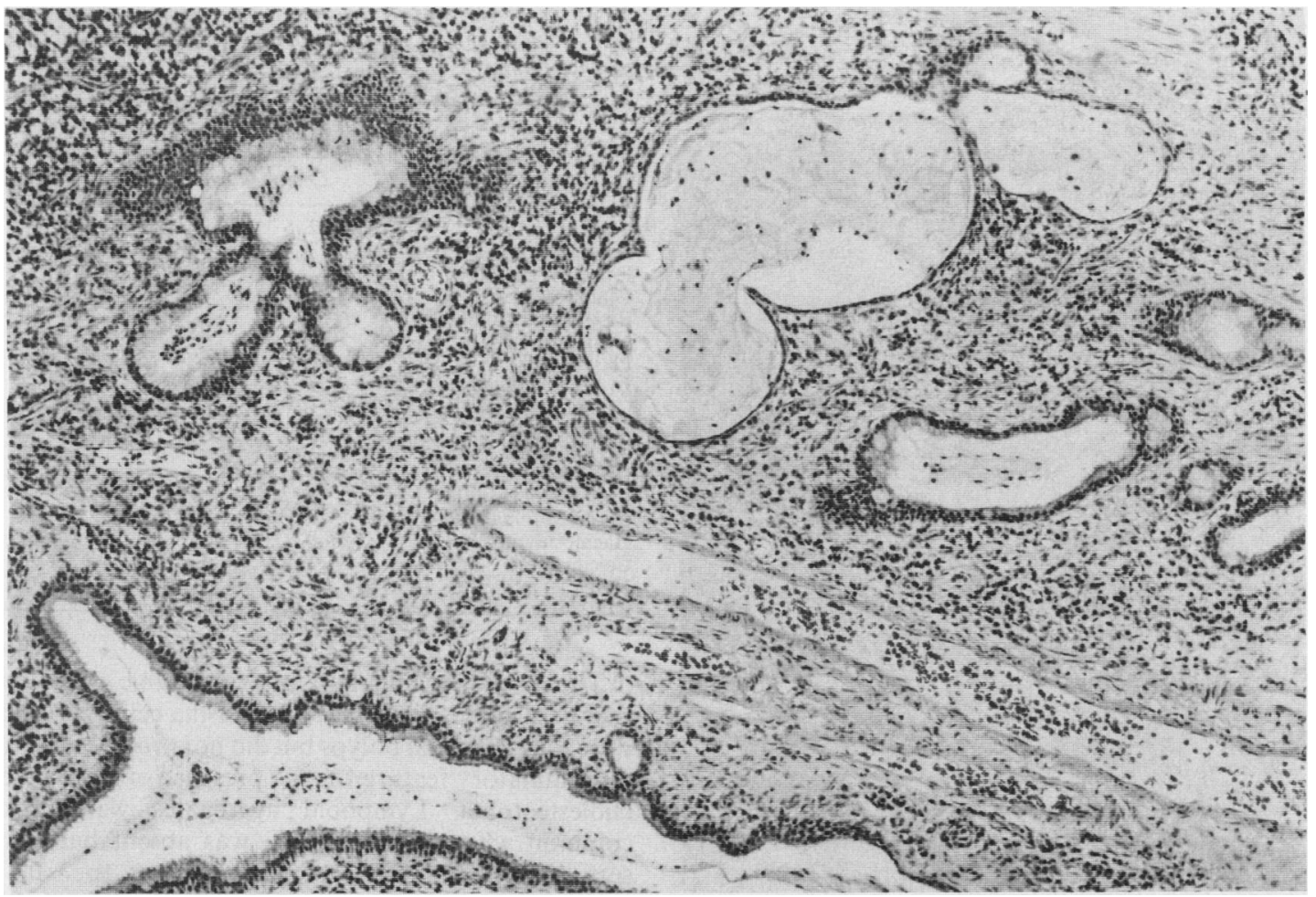

Fig 2 Inflamed core of aural polyp showing mucous glands. (Haematoxylin and eosin.)

\section{HISTOLOGICAL FEATURES}

From the results of a pilot study the presence or absence of 16 possible features were scored. These are conveniently divided into groups as follows:

Type of polyp

1 Covering epithelium (fig 1). The presence or absence was noted regardless of histological type.

2 Connective tissue core (fig 1 )

3 Mucous glands (fig 2)

4 Raw granulation tissue without a covering epithelium (fig 3)

\section{Type of inflammation}

1 Neutrophils

2 Plasma cells

3 Lymphoid aggregates (fig 4)

4 Germinal centres (fig 4)

\section{Special features}

1 Keratin as masses (fig 5)

2 Keratin as flakes (fig 6)

3 Multinucleated giant cells (fig 5)

4 Cholesterol granuloma
5 Wall of cholesteatoma sac

6 Haemosiderin deposits

7 Calcification

8 Hair

Clinical information was determined retrospectively from the patient records and subsequently matched up with the histological data.

All patients were followed up for at least three months after polypectomy; many patients were followed up for much longer, in some cases for 10 years or more. After diagnosis of cholesteatoma is confirmed it is policy in the ear, nose, and throat department to follow up patients at intervals for life. Patients without cholesteatoma are discharged when indicated clinically. Experience in the Bristol catchment area shows that any further aural problems usually lead to rereferral to the same specialist.

Significance of difference among the features in polyps associated with an underlying cholesteatoma and polyps not associated with underlying cholesteatoma were compared using the $\chi^{2}$ test, or Fisher's exact probability test where any feature numbered less than 5. Results were then separately examined using multiple stepwise regression analysis. 


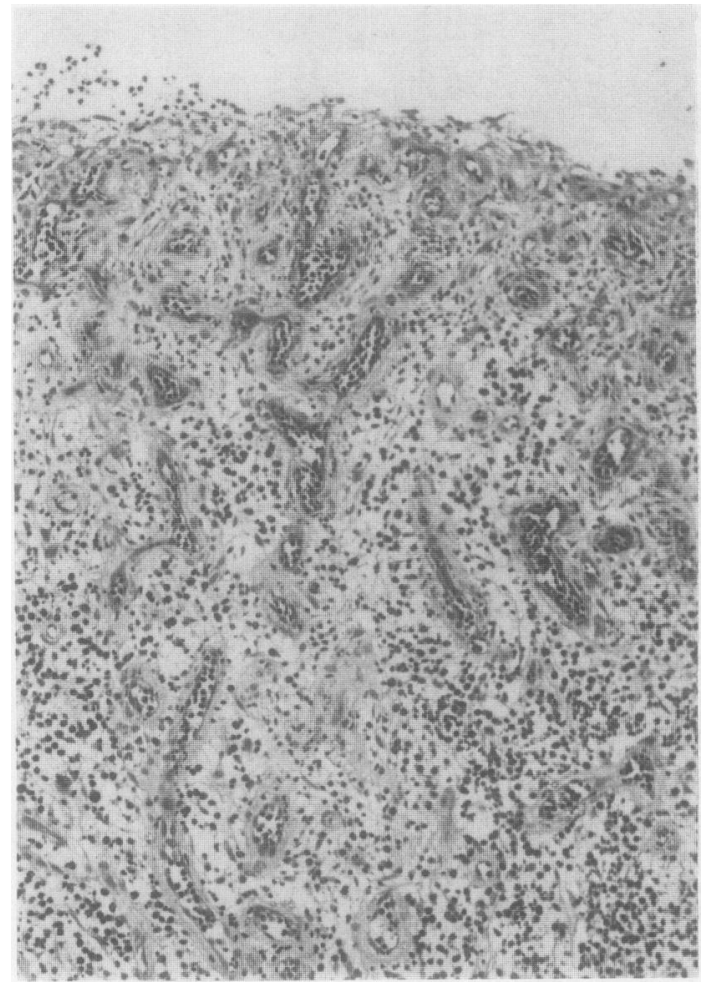

Fig 3 Aural polyp comprising raw granulation tissue with no surface epithelium and no fibrous core. (Haematoxylin and eosin.)

\section{Results}

From the retrospective study of the patients' records, cholesteatoma was found in 42 of 96 patients, 40 of whom received surgery. Of the 54 patients in whom there was no cholesteatoma, eight had exploratory surgery for the further investigation of attic retraction pockets.

The results of scoring for the type of polyp are shown in table 1 . The results indicate that certain histological features were much more common in the absence of an underlying cholesteatoma. A polyp composed of a fibrous core with a covering epithelium was not associated with cholesteatoma in $70 \%$ of cases; only $25 \%$ of those polyps associated with underlying cholesteatoma had these features present $(0.05>\mathrm{p}>0.02)$. Glands were uncommon in either group but were more common when cholesteatoma was absent $(0 \cdot 1>p>0.05)$. In contrast, among polyps which were associated with underlying cholesteatoma raw granulation tissue was twice as likely as in the polyps which were not so associated $(0.05>\mathrm{p}>0.02)$.
Table 1 Prevalence of histological features in aural polyps with underlying cholesteatoma and no underlying cholesteatoma

\begin{tabular}{lll}
\hline & \multicolumn{2}{c}{ Clinical outcome } \\
\cline { 2 - 3 } Histological features & Cholesteatoma & No cholesteatoma \\
\hline Total & 42 & 58 \\
Epithelium & 13 & 39 \\
Fibrous core & 11 & 39 \\
Glands & 5 & 19 \\
Raw granulation tissue & 29 & 19 \\
Neutrophils & 30 & 38 \\
Plasma cells & 39 & 56 \\
Lymphoid aggregates & 7 & 21 \\
Germinal centres & 3 & 4 \\
Keratin masses & 25 & 9 \\
Keratin flakes & 21 & 12 \\
Giant cells & 19 & 17 \\
Cholesterol granuloma & 1 & 2 \\
Cholesteatoma sac & 2 & 0 \\
Haemosiderin & 9 & 3 \\
Calcification & 1 & 2 \\
Hair & 3 & 1 \\
\hline
\end{tabular}

The results for inflammatory cells (table 1 ) showed that neutrophils $(p>0.5)$ and plasma cells $(p>0.5)$ were found in most polyps but did not provide a useful discriminatory feature for the presence or absence of cholesteatoma. Lymphoid aggregates were more common when cholesteatoma was absent but were seen in less than half of these polyps $(p>0 \cdot 1)$. Germinal centres were rare in either group and this feature was also non-discriminatory $(p>0.5)$.

The special features that scored as possible indicators of cholesteatoma are shown in table 1 . Keratin, either as masses $(0.01>p>0.001)$ or as individual flakes $(0.05>p>0.02)$, occurred more often if there was an underlying cholesteatoma than in reactive polyps associated with "safe" noncholesteatoma middle ear disease. Giant cells did not provide a useful discrimination $(p>0.5)$. Haemosiderin was seen occasionally, but when present was most often associated with cholesteatoma $(0.02>p>0.01)$. The other features recorded were seen only in a very few polyps and most were unhelpful.

The histological features were then analysed by stepwise multiple regression analysis. Polyps composed of raw granulation tissue and containing either keratin as masses or flakes gave the best correlation for cholesteatoma $(r=0.73)$ and similarly polyps composed of a pre-existing fibrous core with a covering epithelium and containing either glands or lymphoid aggregates gave the best correlation for absence of an underlying cholesteatoma $(r=0.80)$. The other factors did not contribute significantly.

Using the findings which provided the best discrimination, the polyps were then resorted into three categories designated as having a high probability, or a 
Fig 4 Aural polyp covered by respiratory epithelium. Core contains lymphoid aggregates with germinal centres. (Haematoxylin and eosin.)
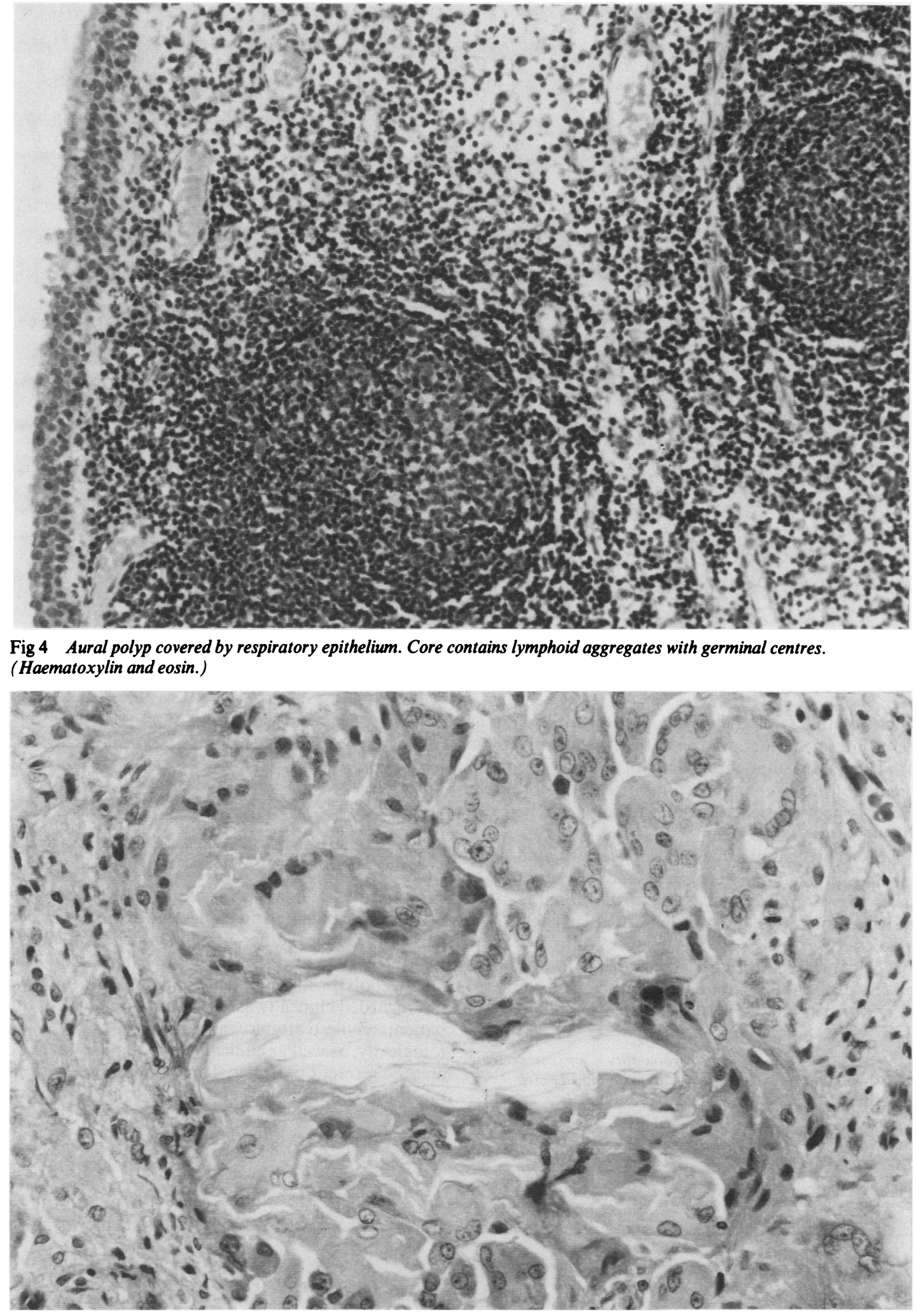


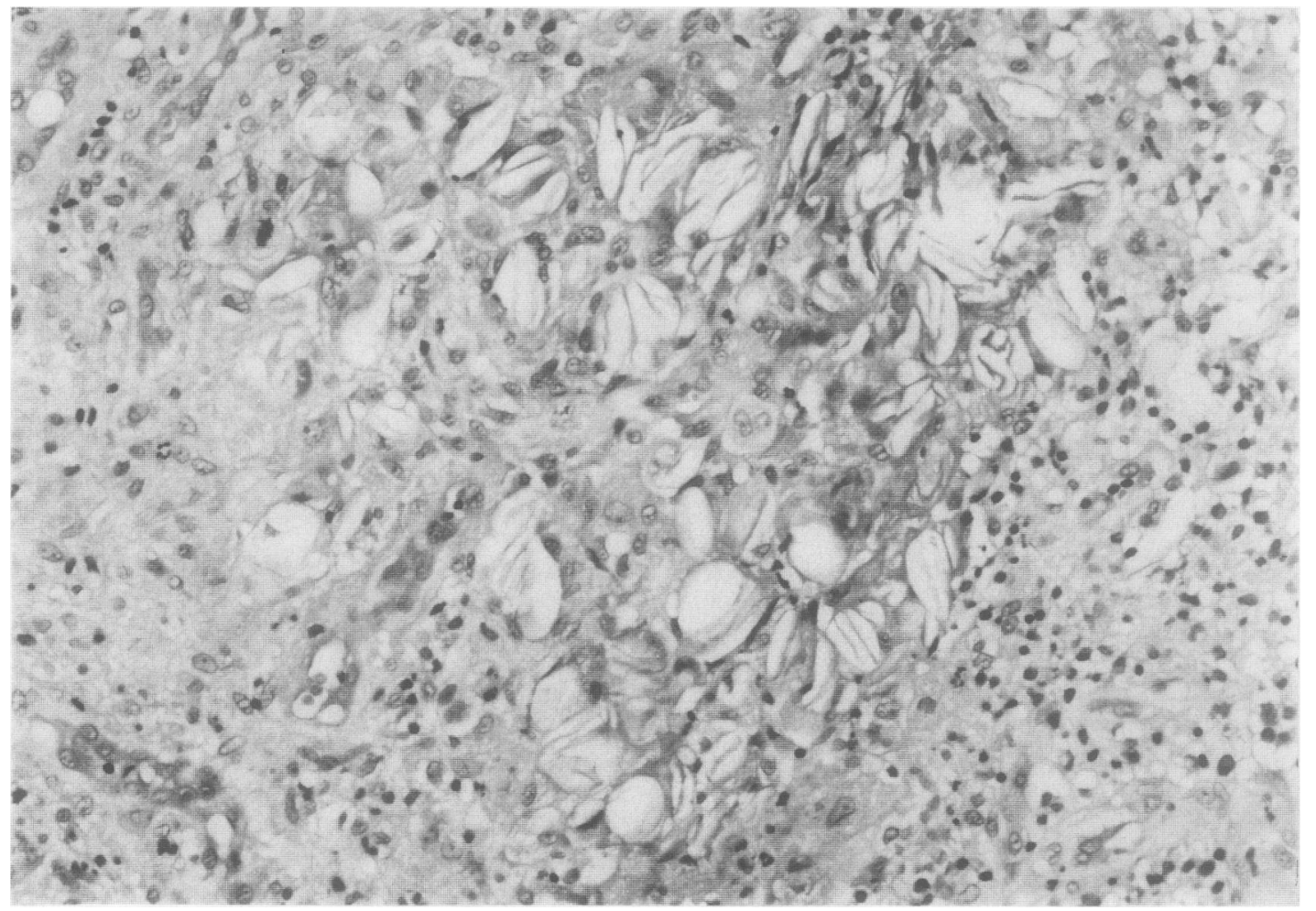

Fig 6 Core of aural polyp containing keratin as flakes, with an associated macrophage and multinucleated giant cell reaction. (Haematoxylin and eosin.)

low probability of underlying cholesteatoma, or as being intermediate (raw granulation tissue only) (table 2). They show that the chance of making a correct prediction from a combination of features for either the presence or absence of cholesteatoma was between $70-80 \%$ ( $p<0.0001)$.

Polyps which provided false negative and false positive predictions were recut and re-examined at several levels, but in no case were additional features shown which would have led to a change in the prediction.

The clinical features of those patients in whom the presence of cholesteatoma was incorrectly predicted were further analysed (table 3). Five patients had

Table 2 Prediction of probability of underlying cholesteatoma from histological features of aural polyp

\begin{tabular}{|c|c|c|c|}
\hline \multirow{2}{*}{$\begin{array}{l}\text { Prediction from } \\
\text { histological features }\end{array}$} & \multirow{2}{*}{$\begin{array}{l}\text { Number } \\
\text { in each } \\
\text { group }\end{array}$} & \multicolumn{2}{|c|}{ Clinical outcome } \\
\hline & & Cholesteatoma & a Not cholesteatoma \\
\hline $\begin{array}{l}\text { Cholesteatoma probable } \\
\text { Cholesteatoma unlikely } \\
\text { Intermediate chance }\end{array}$ & $\begin{array}{l}(40) \\
(50) \\
(10)\end{array}$ & $\begin{array}{l}28(20 \mathrm{M}: 8 \mathrm{~F}) \\
11(\mathrm{GM}: 5 \mathrm{~F}) \\
3(\mathrm{OM}: 3 \mathrm{~F})\end{array}$ & $\begin{array}{l}12(6 \mathrm{M}: 6 \mathrm{~F}) \\
39(26 \mathrm{M}: 13 \mathrm{~F}) \\
7(2 \mathrm{M}: 5 \mathrm{~F})\end{array}$ \\
\hline
\end{tabular}

Table 3 Analysis of false positive results

Chronic otitis media

External auditory polyp

Retraction pocket

Retraction pocket

- intact drum

- no cholesteatoma at surgery

- no surgery

Total

Follow up four-72 months (mean 29 months).

chronic otitis media with central perforation but no retraction pocket and so cholesteatoma had not been part of the clinical differential diagnosis. Similarly, in the three patients who had an external auditory meatus polyp with an intact drum cholesteatoma was not regarded clinically as a serious possibility. In four patients cholesteatoma was a strong possibility histologically, as well as clinically, due to the presence of an attic retraction pocket. Three came to surgery and no cholesteatoma was found. In the fourth patient no surgery was undertaken, but no cholesteatoma became evident on long term follow up.

\section{Discussion}

For the surgeon the decision as to whether or not to 
explore the middle ear for possible cholesteatoma can be difficult, especially in children. This study was done to see whether careful histological examination of aural polyps could be exploited as a way of predicting the presence or absence of underlying cholesteatoma. Standard reference works in otolaryngology ${ }^{3}$ and ear, nose, and throat pathology ${ }^{4}$ have traditionally listed the features which may be found in aural polyps but have not attempted to use these to predict what might be happening in the middle ear.

The results indicate that histological examination of aural polyps can be used to give a prediction of the presence or absence of an underlying cholesteatoma. In particular, the finding of a combination of raw granulation tissue, with keratin as masses or flakes in an aural polyp, makes the presence of an underlying cholesteatoma highly likely, with a probability of between $70-80 \%$. Conversely, the absence of these features, coupled with the presence of a covering epithelium, a connective tissue core, glands and lymphoid aggregates, provide a $70-80 \%$ probability of there being no underlying cholesteatoma. When combined with the clinical impression, these can be used to sharpen the diagnostic accuracy of the investigating surgeon. At the Bristol Royal Infirmary we now incorporate this type of predictive information routinely into all histological reports of aural polypectomy specimens.

Mr Cliff Jeal is thanked for his expert photographic assistance. Valerie Hayne and Barbara Hogg are thanked for their secretarial assistance.

\section{References}

1 Beales PH. Management of chronic suppurative otitis media. In: Ballantyne J, Groves J, eds. Scott-Brown's diseases of the ear, nose and throat. 4th ed. London: Butterworths, 1979:259-304.

2 Proctor B. Chronic otitis media and mastoiditis. In: Paparella MM, Shumrick DA, eds. Otolaryngology. 2nd ed. Philadelphia: WB Saunders, 1980:1455-89.

3 Meyerhoff MD. Granulomas and other specific diseases of the ear and temporal bone. In: Paparella MM, Shumrick DA, eds. Otolaryngology. 2nd ed. Philadelphia: WB Saunders, 1980:1548.

4 Michaels L. Ear, nose and throat histopathology. Berlin: SpringerVerlag, 1987:25-39,41-54

Requests for reprints to: Dr C M Milroy, Department of Histopathology, University College and Middlesex School of Medicine, Rockefeller Building, University Street, London WC1E 6JJ, England. 